\title{
ELECTROLYTIC CAPACITOR ONLINE FAILURE DETECTION AND LIFE PREDICTION METHODOLOGY
}

\author{
A. R. Khandebharad ${ }^{1}$, R. B. Dhumale ${ }^{2}$, S. S. Lokhande ${ }^{3}$ \\ ${ }^{l}$ Department of Electronics and Telecommunication, Sinhgad college of engineering, Pune, India \\ ${ }^{2}$ Department of Electronics and Telecommunication, Sinhgad college of engineering, Pune, India \\ ${ }^{3}$ Department of Electronics and Telecommunication, Sinhgad college of engineering, Pune, India
}

\begin{abstract}
Various basic, efficient and cheap techniques are used for the purpose of life forecast and failure detection of aluminum electrolytic capacitors which are utilized as a part of many power electronic converters. The main idea of these techniques is to calculate the values of Equivalent Series Resistance (ESR) and Capacitance (C). Observing the ESR values, valuation of changes in voltage and current of electrolytic capacitor, can gauge the well being state of the converter as well as life period of capacitor. But these techniques fails to consider all four parameters temperature, frequency, voltage and current simultaneously that affect the life period of electrolytic capacitor. The goal of this paper is to propose a comprehensive platform for electrolytic capacitor life period estimation. Proposed method consider all parameters that are limiting age of Aluminium electrolytic capacitor in switched power DC-DC buck converter.
\end{abstract}

Keywords: $E S R, C, K_{T}, K_{V}, K_{R}, K_{F}, L_{O}, L_{X}$ and DC-DC power converter.

\section{INTRODUCTION}

Aluminum electrolytic capacitor is mainly used in power electronic converters. The failures of the power converters results in electronic system failure. Most of the time undesired output is resulted from malfunctioned behavior of electrolytic capacitor. It is absolutely clear from previous researches that Aluminium electrolytic capacitor has a finite useful light [1]-[21].

There are many reasons and patterns of failure of electrolytic capacitors. Mainly failure of aluminium electrolytic capacitors is due to the evaporation of electrolytic solution. Equivalent series resistance (ESR) of capacitor will increase and capacitance $(C)$ will decrease as the working hours of capacitor will increase. Operating temperature rise will again accelerate the process, which will increase the power losses. Considerable changes can be seen in Capacitor characteristics [1]-[9].

The purpose of this paper is to review the degradation mechanism of aluminium electrolytic capacitors, equivalent circuit models, life prediction models and failure detection techniques and then propose more accurate and inclusive method considering all age affecting factors which will predict life period aluminium electrolytic capacitor used in a switched power DC-DC buck converter.

\section{EQUIVALENT CIRCUIT MODEL OF}

\section{ELECTROLYTIC CAPACITOR}

Aluminium electrolytic capacitor have two aluminium electrodes, one as an anode and another as a cathode and separator paper is soaked in an electrolyte solution.[1] The dielectric is an oxide layer $\left(\mathrm{Al}_{2} \mathrm{O}_{3}\right)$ which formed electrochemically on the surface of the anode.[2] Low cost, large capacity, energy storage and voltage regulation are the main reasons of electrolytic capacitor for being used in power converters.[3]

Generally there are two models used for modelling the equivalent circuit of electrolytic capacitors as shown in Fig. 1 and Fig. 2. [1]-[7] Practically lead inductance is kept as small as possible and therefore the value of the equivalent series inductance (ESL) becomes much smaller than the ESR. Value of leakage current is considered as negligible. The equivalent circuit for the electrolytic capacitor considering all component losses is simplified as series combination of Capacitor (C) and ESR as shown in Fig. 3. [1]-[9]

Malfunctioned behavior of Aluminium electrolytic capacitors is due to reasons such as short circuit, open circuit, increase of leakage current, electrolyte vaporization, etc. But main reason of degradation is the vaporization of electrolyte. When the volume of electrolyte decreases, the value of ESR will increase and $\mathrm{C}$ will decrease.

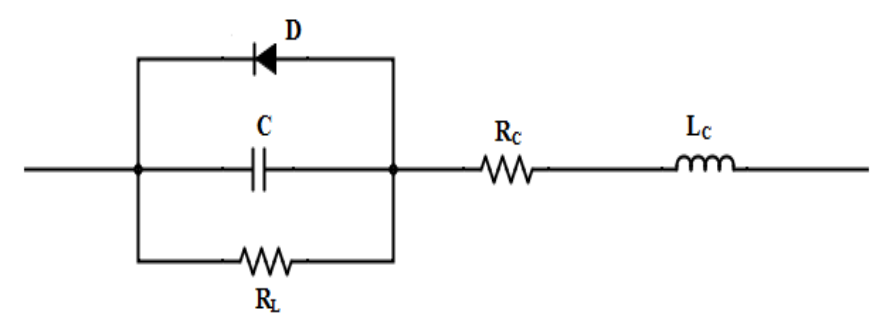

Fig-1: Equivalent circuit of electrolytic capacitors 


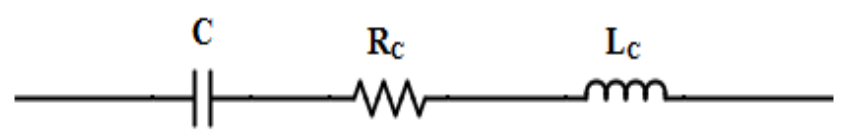

Fig-2: Simplified model of electrolytic capacitors

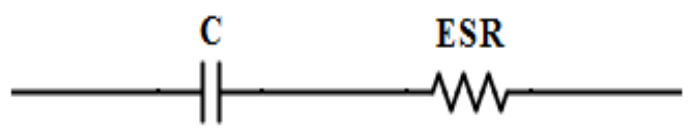

Fig-3: Reduced model of electrolytic capacitors

The increasing value of ESR will results in additional power loss, increasing internal temperature and accelerated evaporation of the electrolyte.[7] The capacitor is considered to be failed when its $40 \%$ of the electrolyte is consumed.[1]-[8] The volume measurement of electrolyte can't be conducted, and hence ESR is used to predict failure and also to analyze life period.

The relationship between ESR and the volume of electrolyte can be expressed as shown in Equation (1) . Where $\mathrm{ESR}_{0}$ is the initial value of ESR, $\mathrm{V}_{0}$ is the initial volume of electrolyte. Researchers have calculated that when $40 \%$ of the electrolyte is consumed then ESR will become about 2.8 to 3 times of initial value of ESR and capacitor is considered as failed [1][7][8].

$$
\frac{\mathrm{ESR}}{\mathrm{ESR}_{0}}=\left(\frac{\mathrm{V}_{0}}{\mathrm{~V}}\right)^{2}
$$

\section{FAILURE DETECTION METHODS}

Numerous methods have been proposed for failure detection, which mainly focus on the ESR of the electrolytic capacitor [1]-[14],[17]. Numerous parameters, for example, current or temperature need to be measured, which increases intricacy and accuracy of the measurement. Failure detection methods can be classified into two sections, online and offline failure prediction methods. Most of the methods use power converters for their application.

A ratio of the capacitor voltage to the capacitor current or load current method has been widely used with converters [1]-[9]. Some method consider current as constant source and failure detection is done only using output voltage ripple.[7] Many methods have considered ratio of mean value of ripple voltage and ripple current at different switching instances. Almost all the methods only vary their measurement positions and/or measurement instances, but parameters are same and that are voltage and current[1][13].

Again methods are differentiated on basis of techniques used for the measurement of parameters. Methods based on sensors are more precise than the methods which are sensor less with hardware precision overhead[1]-[8]. Some methods differ by their processing techniques used such as least square or recursive least square method, Empirical Mode Decomposition (EMD) algorithms that are used to process data[17].

Methods also differ by the processing hardware used. Digital signal processors, computers and spatially designed systems are utilized[8][11]. Various methods have preferred to use oscilloscope, ripple current tester, data acquisition systems from National Instruments to collect data[7][8]. Method have also formulated temperature relation in failure detection. One method has used capacitor electrolytic temperature to evaluate electrolytic volume for calculation of ESR[14].

\section{LIFE PREDICTION MODEL}

Electrolytic capacitors have limited but indefinite life period. Life time may vary due to different operating conditions and also it is dependent on various physical factors. Life prediction model is generally graphical which is included in datasheets of capacitors. Another method is to use formulation based on different parametric factors[1],[14]-[21].

There are four major parameters voltage, current, switching frequency and temperature that affects the life period of electrolytic capacitor.[1][7][8][21]. Parameters in operation are used along with standard life time mentioned in the datasheets for the resulting life time estimation. Many others have proposed techniques based only on some specific parameters. They haven't considered all parameters for the estimation at the same time [1]-[20].

\subsection{Temperature Factor $\left(K_{T}\right)$ :}

The Temperature Factor $\left(\mathrm{K}_{\mathrm{t}}\right)$ is based on 10 Kelvin rule. A drop of the ambient temperature by $10 \mathrm{~K}$ doubles the lifetime. The formula can be given as follows :

$$
\mathrm{K}_{\mathrm{T}}=2^{\frac{\mathrm{T}_{\mathrm{p}}-\mathrm{T}_{\mathrm{g}}}{10}}
$$

Where,

$\mathrm{T}_{0}$ : Upper category temperature

$\mathrm{T}_{\mathrm{a}}:$ Ambient temperature in the application

\subsection{Ripple Current Factor $\left(K_{R}\right)$ :}

The effect of ripple current of electrolytic capacitors on the life period can be given by ripple current factor as :

$$
\mathrm{K}_{\mathrm{R}}=\mathrm{K}_{\mathrm{i}}^{\mathrm{A}} \cdot \frac{\Delta \mathrm{T}_{\mathrm{p}}}{10}
$$

Where,

$$
\begin{gathered}
A=1-\left(\frac{I_{a}{ }^{a}}{I_{a}}\right)^{2} \\
I_{a}{ }^{g}=\frac{I_{a}}{K_{F}}
\end{gathered}
$$


And

$\mathrm{I}_{\mathrm{a}}$ : Ripple current in application

$\mathrm{I}_{\mathrm{a}}{ }^{\mathrm{\sigma}}$ : Frequency normalized ripple current

$\mathrm{K}_{\mathrm{F}}$ : Frequency factor

$\mathrm{I}_{0}$ : Nominal ripple current at upper category temperature

$\Delta \mathrm{T}_{0}:$ Core temperature increase of the electrolytic capacitors (typ. $5 \mathrm{~K}$ at $\mathrm{T} 0=105^{\circ} \mathrm{C}$ and $10 \mathrm{~K}$ at $\mathrm{T} 0=85^{\circ} \mathrm{C}$ )

$\mathrm{K}_{\mathrm{i}}$ : Empirical safety factor, defined as :

If $\mathrm{T}_{0}=105^{0}$ then for $\mathrm{I}>\mathrm{I}_{0} ; \mathrm{K}_{\mathrm{i}}=4$

$\mathrm{I} \leq \mathrm{I}_{0} ; \mathrm{K}_{\mathrm{i}}=2$

If $\mathrm{T}_{0}=85^{\circ}$ then $\mathrm{K}_{\mathrm{i}}=2$

\subsection{Voltage Factor $\left(\mathrm{K}_{\mathrm{V}}\right)$ :}

The influence of actual operating voltage of electrolytic capacitors on the lifetime of electrolytic capacitors can be given as :

$$
\mathrm{K}_{\mathrm{V}}=\left(\frac{\mathrm{U}_{\mathrm{z}}}{\mathrm{U}_{\mathrm{r}}}\right)^{-\mathrm{n}}
$$

Where,

$\mathrm{U}_{\mathrm{r}}:$ Rated voltage

$\mathrm{U}_{\mathrm{a}}$ : Actual operating voltage

$\mathrm{n}$ : exponent (selected according to manufacturer.)

\subsection{Frequency Factor $\left(K_{F}\right)$ :}

The frequency also creates an impact on the life period of electrolytic capacitors. The ratio of actual ripple current measured and the frequency factor shown below is used to get frequency compensated ripple current for the life period estimation:

$$
\mathrm{K}_{\mathrm{F}}=\sqrt{\frac{\operatorname{ESR}_{0}}{\operatorname{ESR}_{\mathrm{f}}}}
$$

Where,

$\mathrm{ESR}_{0}$ : ESR at nominal frequency (generally at $100 \mathrm{~Hz} / 120 \mathrm{~Hz})$

$\mathrm{ESR}_{\mathrm{f}}:$ ESR at operating frequency.

For the proposed method ESR will be calculated by using sensed voltage and ripple current.

\subsection{The Structure of Life Time Model:}

The life time model is based on some specific parameters from the datasheet and some specific parameters in application. Standard reference life time from datasheet is multiplied with the impact factors of these parameters to estimate resulting life time as follows:

$$
\mathrm{L}_{\mathrm{X}}=\mathrm{L}_{0} \cdot \mathrm{K}_{\mathrm{T}} \cdot \mathrm{K}_{\mathrm{R}} \cdot \mathrm{K}_{\mathrm{V}}
$$

Where,

$\mathrm{L}_{\mathrm{X}}$ : Resulting lifetime

$\mathrm{L}_{0}$ : Lifetime at nominal ripple and upper category temperature.

\section{PROPOSED METHOD}

The proposed method for the online failure prediction of electrolytic capacitors will be based the life time model using all parametric effects as discussed in IV-E section. A DC-DC converter with an LC filter will be implemented using a simple switcher with fixed frequency. Adjustable output voltage and current range is up to $3 \mathrm{~A}$. The radial electrolytic capacitor used is of $470 \mu \mathrm{F}, 50 \mathrm{~V}, 105^{\circ} \mathrm{C}$.

Capacitor ripple current and output voltage along with the ambient temperature in application is acquired using data acquisition system and will be processed using Digital Signal Processor (DSP). The implementation of the system is done using high resolution analog to digital converter, a DSP and a interface board that is ADS8380EVM, TMS320C6713 DSK and 5-6K interface board respectively.

This system setup is more precise and will provide required resolution for the precise lifetime estimation. DSP supports floating point operations and ADC has 18 bit resolution. Entire circuit can be enclosed in a temperature controlled cube which will bring more accurate and steady temperature readings.

Block diagram of proposed method is shown in fig. 4. this method is easy, more accurate and inclusive. By varying various parameters, we will be able to see the change in lifetime directly on the display. 


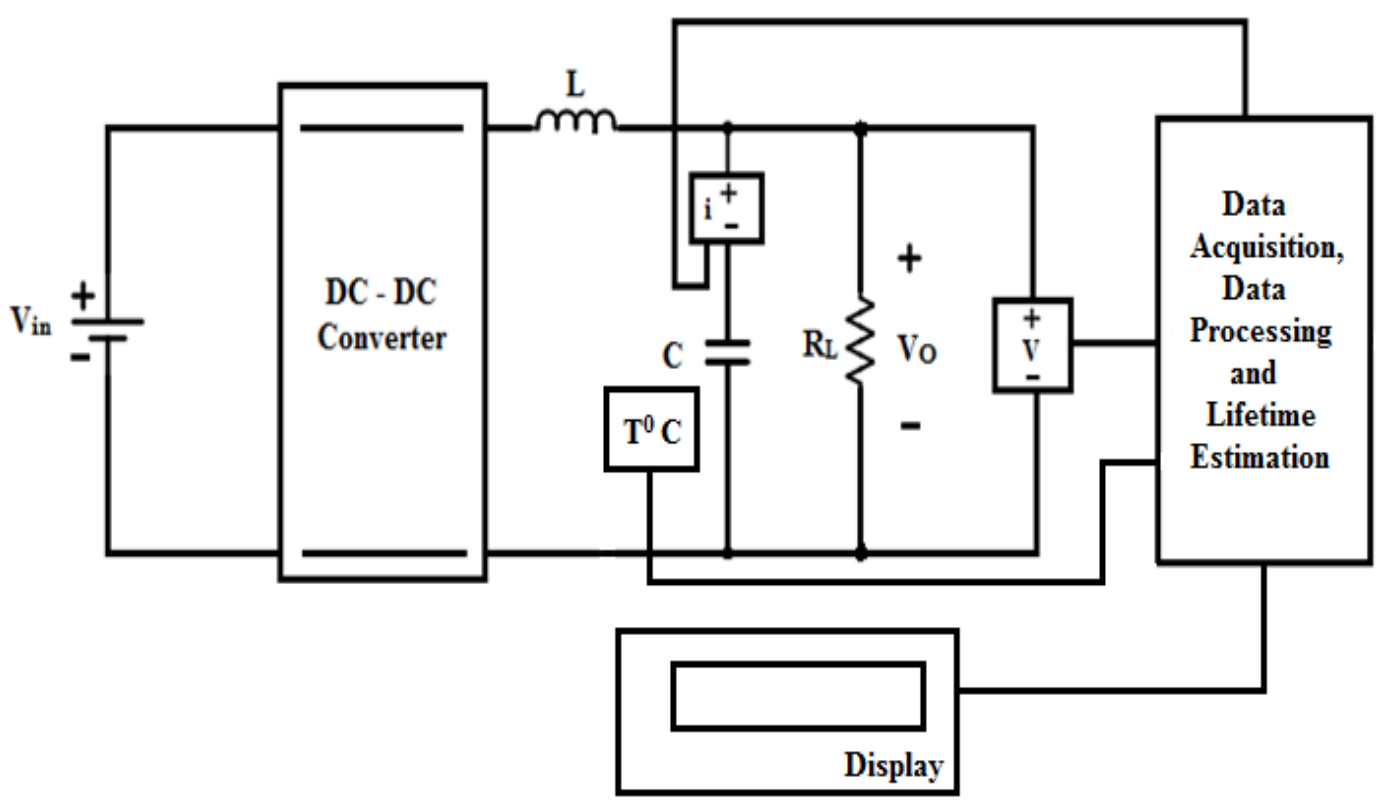

Fig-4 : Block diagram of proposed method.

\section{SIMULATION RESULTS:}

Estimation of the life period of electrolytic capacitor based on life prediction model using all parameters is done using MATLAB Simulink. For this simulation a simple DC-DC converter is implemented and capacitor prognosis is carried out using all four parameters in operation and lifetime model.

The fig. 5 shows the complete system and fig. 6 shows the capacitor prognosis model. The hardware implementation will give accurate results, if precise data acquisition system is constructed. Consideration of all capacitor life affecting is the main advantage of this method.

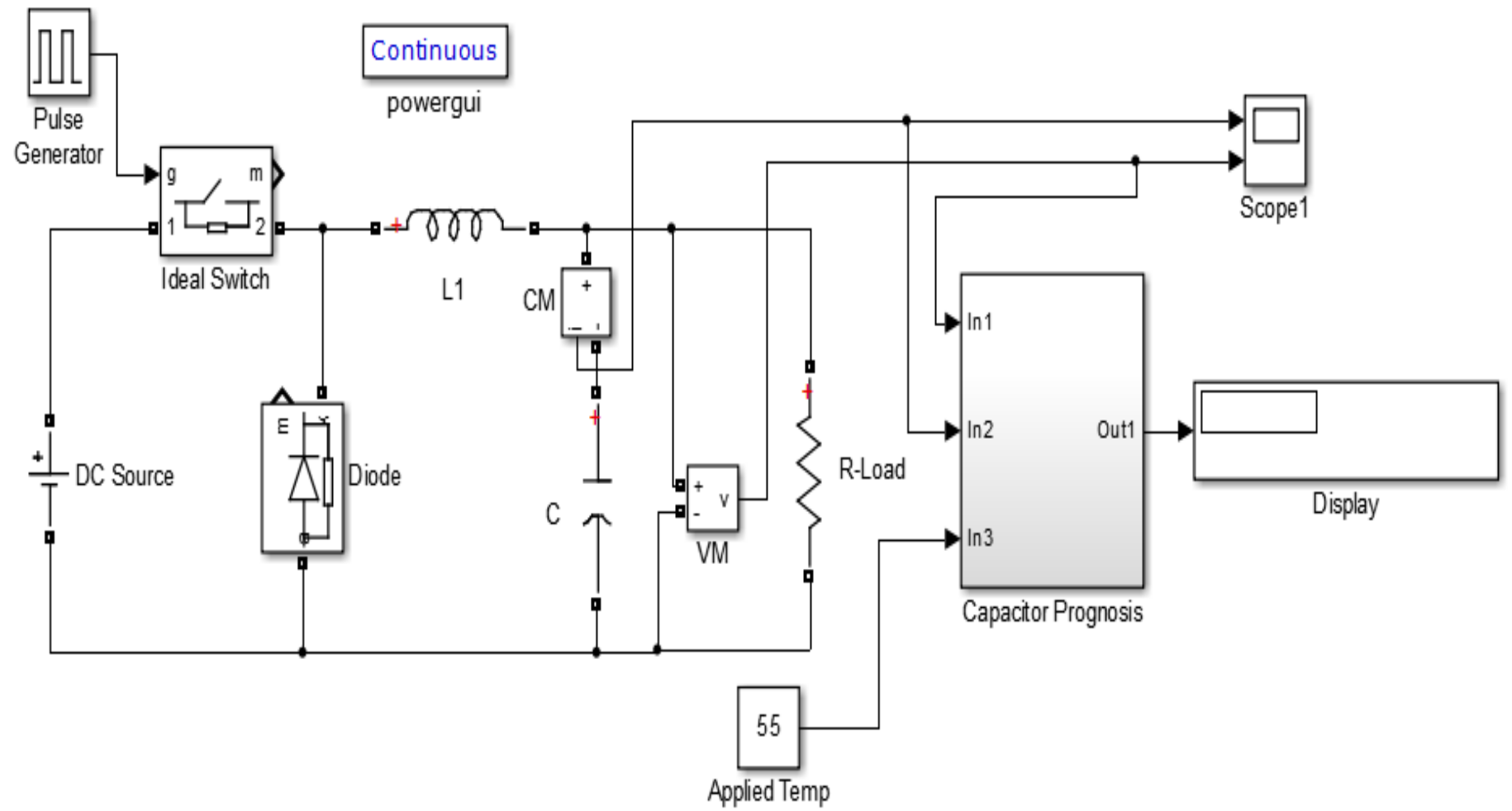

Fig-5: Simulation of complete system of proposed method 


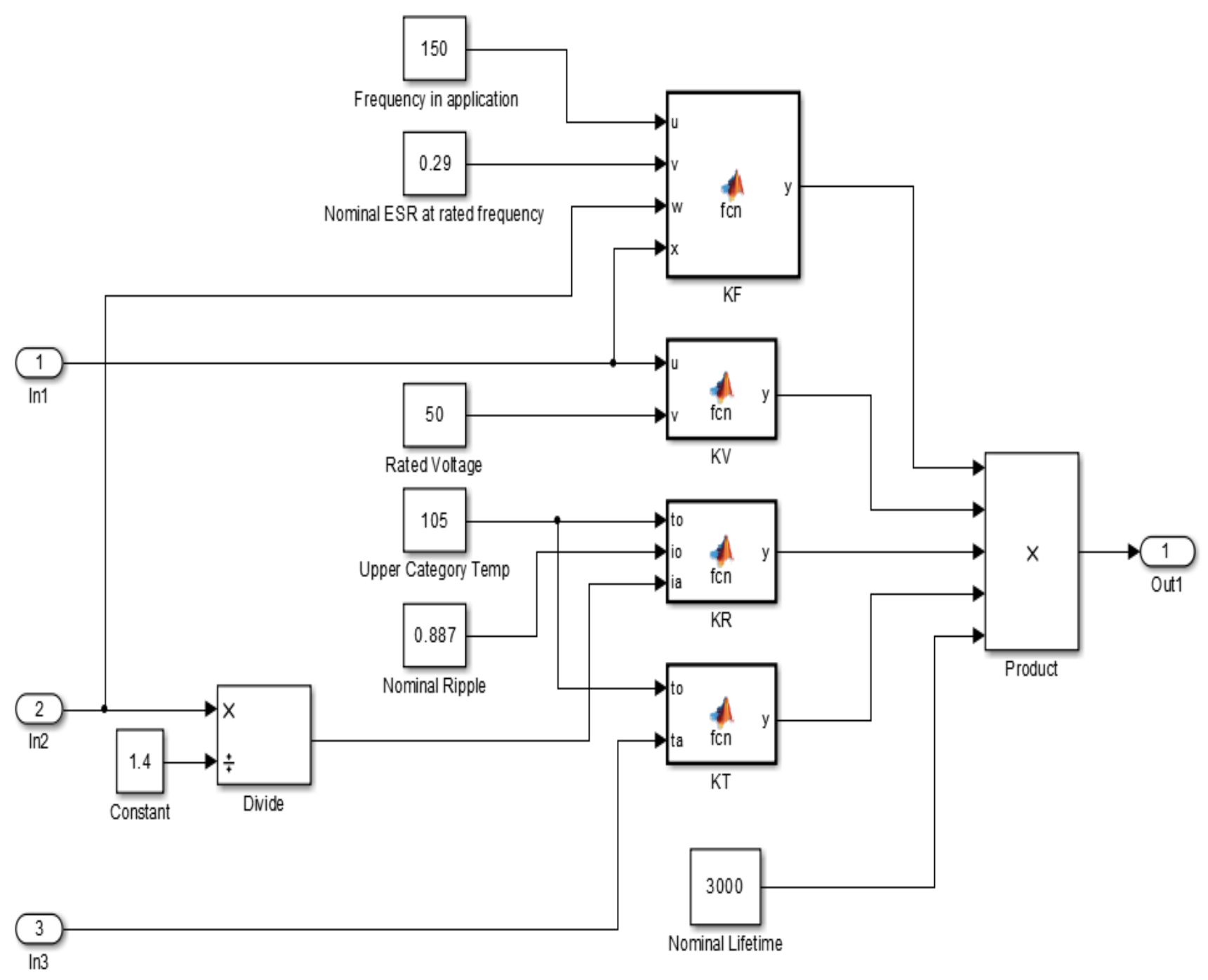

Fig-6: Simulation of Capacitor prognosis model.

The selected capacitor has following nominal parameters given in the datasheet.

$\mathrm{L}_{0}=3000 \mathrm{~h}$;

$\operatorname{ESR}_{0}=0.29 \Omega ;$

$\mathrm{U}_{\mathrm{r}}=50 \mathrm{~V} ;$

$\mathrm{T}_{\mathrm{o}}=105^{\circ} \mathrm{C}$

$\Delta \mathrm{T}_{0}=5 \mathrm{~K}$

$\mathrm{I}_{0}=0.887 \mathrm{~A}$;

$0.5 \leq \frac{\mathrm{U}_{\mathrm{a}}}{\mathrm{U}_{\mathrm{r}}}<0.8 \rightarrow n=3$

$0.8 \leq \frac{\mathrm{U}_{\mathrm{a}}}{\mathrm{U}_{\mathrm{r}}}<1.0 \rightarrow n=5$
The operational parameters are as follows :

$\mathrm{T}_{\mathrm{a}}=55^{\circ} \mathrm{C}$;

$\mathrm{I}_{\mathrm{a}}=1.78 \mathrm{~A}$;

$\mathrm{K}_{\mathrm{i}}=4$;

$\mathrm{U}_{\mathrm{a}}=36 \mathrm{~V} ;$

$\mathrm{F}_{\mathrm{s}}=150 \mathrm{kHz}$;

Generally $\mathrm{K}_{\mathrm{F}}=1$.

The resulting lifetime of the selected aluminium electrolytic capacitor at the given operating conditions by using proposed method will be :

$$
\mathrm{L}_{\mathrm{X}}=31551.80 \mathrm{~h}
$$




\section{CONCLUSION}

The electrolytic capacitors are commonly used in the switching-mode power converters. These capacitors have limited time period. Therefore, it is necessary to predict the lifetime of the electrolytic capacitor for reliability assessment of power converters. Different methods used for the failure prediction of electrolytic capacitor are reviewed in this paper.

Experimental measurements will be done on the electrolytic capacitors under different operation conditions for the life time prediction using a well structured and parameterized life time model. Simulation of the proposed method is concluded in this paper. The new method will be implemented practically to realize the online failure prediction of the electrolytic capacitor of an LC filter in the switching-mode DC-DC power converter.

\section{REFERENCES}

[1] Yong Yu, Tao Zhou, Mingjun Zhu, Dianguo Xu, "Fault Diagnosis and Life Prediction of DC-link Aluminum Electrolytic Capacitors used in threephase AC/DC/AC converters," in IMCCC, 2012, pp.825-830.

[2] Hao Ma, Linguo Wang, "Fault diagnosis and failure prediction of Aluminum electrolytic capacitors in power electronic converters," Industrial Electronics Society, IECON 2005, 31st Annual Conference of IEEE, 2005, pp. 842-847.

[3] A.Amaral and A. Cardoso, "An experimental technique for estimating the aluminum electrolytic capacitor equivalent circuit, at high frequencies," in Proc. IEEE Int. Conf. Ind. Technol., 2005, pp. 8691.

[4] K. Lee, M. Kim, J. Yoon, S.B. Lee, and J. Yoo, "Condition Monitoring of DC Link Electrolytic Capacitors in Adjustable Speed Drives," IEEE Transactions on Industry Applications, vol. 44, no. 5, Sept./Oct. 2008, pp. 1606-1613.

[5] K. Abdennadher, P. Venet, G. Rojat, J.-M. Retif, and C. Rosset, "A Real-Time Predictive Maintenance System of Aluminum Electrolytic Capacitors Used in Uninterrupted Power Supplies," IEEE Transactions on Industry Applications, vol. 46, no. 4, July/August 2010, pp. 1644-1652.

[6] M. Gasperi, "Life prediction modeling of bus capacitors in AC variable frequency drives," IEEE Trans. Ind. Appl., vol. 41, no. 6, pp. 14301435,Nov./Dec. 2005.

[7] Yaow-Ming Chen, Hsu-Chin Wu, Ming-Wei Chou, and Kung-Yen Lee, "Online Failure Prediction of the Electrolytic Capacitor for LC Filter of Switching-Mode Power Converters," IEEE Trans. Ind. Electron., vol. 55, no. 1, Jun. 2008.

[8] Gustavo Malagoni Buiatti, Juan A. Martín-Ramos, Carlos H. Rojas García, Acácio M. R. Amaral, Antonio J. Marques Cardoso, "An Online and Noninvasive Technique for the Condition Monitoring of Capacitors in Boost Converters,"
IEEE Trans. Inst. and Meas., vol. 59, no. 8, pp. 2134-2143,Aug. 2010.

[9] A. Amaral and A. Cardoso, "Use of ESR to predict failure of output filtering capacitors in boost converters," in Proc. IEEE Int. Symp. Ind.Electron., 2004, pp. 1309-1314.

[10] P. Venet, F. Perisse, M. H. El-Husseini, and G. Rojat, "Realization of a smart electrolytic capacitor circuit," IEEE Ind. Appl. Mag., vol. 8, no. 1, pp. 1620, Jan./Feb. 2002.

[11] A. Imam, T. Habetler, R. Harley, and D. Divan, "Failure prediction of electrolytic capacitor using DSP methods," in Proc. IEEE Appl. Power Electron. Conf. Expo., 2005, pp. 965-970.

[12] A. Lahyani, P. Venet, G. Grellet, and P. Viverge, "Failure prediction of electrolytic capacitors during operation of a switch mode power supply," IEEE Trans. Power Electron., vol. 13, no. 6, pp. 11991207, Nov. 1998.

[13] O. Ondel, E. Boutleux, and P. Venet, "A decision system for electrolytic capacitors diagnosis," in Proc. IEEE Power Electron. Spec. Conf., 2004, pp. 4360-4364.

[14] M. Gasperi, "A method for predicting the expected life of bus capacitors," in Proc. IEEE Ind. Appl. Conf., 1997, pp. 1042-1047.

[15] M. Gasperi, "Life prediction model for aluminum electrolytic capacitors,"in Proc. IEEE Ind. Appl. Conf., 1996, pp. 1347-1351.

[16] Chetan Kulkarni, Gautam Biswas, Xenofon Koutsoukos, Jose Celaya and Kai Goebel, "Integrated Diagnostic/Prognostic Experimental Setup for Capacitor Degradation and Health Monitoring," in AUTOTESTCON, IEEE Conf., 2010, pp. 1-7.

[17] Guohui Wang, Yong Guan, Jie Zhang2, Lifeng Wu, Xueyuan Zhengl, Wei Panl, "ESR Estimation Method for DC-DC Converters Based on Improved EMD Algorithm,” in PHM, IEEE Conf.,2012,pp.16.

[18] Acácio M. R. Amaral and A. J. Marques Cardoso, "An Economic Offline Technique for Estimating the Equivalent Circuit of Aluminum Electrolytic Capacitors," IEEE Trans. on Inst. and Meas., vol. 57, no.12, 2008.

[19] C. Louen, S. X. Ding and C. Kandler, "A new Framework for Remaining Useful Life Estimation Using Support Vector Machine Classifier," in Control and Fault-Tolerant Systems (SysTol), PP. 228-233, 2013.

[20] L. Kovács, D. Fodor and R. Marschalko, "Power Converter Based Test Bench Design for Aluminum Electrolytic Capacitor Development," in IYCE,pp.14, Jun 2013.

[21] Dr. Arne Albertsen, "Electrolytic Capacitor Lifetime Estimation”, in JIANGHAI EUROPE GmbH, 2010. 